\title{
Electrophysiological and Synaptic Characterization of Transplanted Neurons in Adult Rat Motor Cortex
}

\author{
Julio Santos-Torres, Margarita Heredia, Adelaida S. Riolobos, Lydia Jiménez-Díaz, Virginia Gómez-Bautista, \\ Antonio de la Fuente, José M. Criado, Juan Navarro-López, and Javier Yajeya
}

\begin{abstract}
Lesions in specific areas of the rat motor cortex generate deficits related to fine movement performance affecting the forelimb. We have previously shown that transplants of embryonic frontal cortex ameliorate these motor deficits. Amelioration has been associated with a functional integration of the transplant due to the connections established between the host brain and the graft. In the current investigation, the electrophysiological properties of the transplanted cells and the connections both intra-transplant and with the adjacent host cortex are analyzed. For this purpose, adult rats with a motor cortical lesion plus a fetal cortical graft were used. Neurons in the transplant were recorded using sharp electrodes or whole-cell recordings in brain slices. Application of intracellular depolarizing pulses showed two patterns of cell firing: regular and burst spiking. Postsynaptic responses evoked by both, intra-transplant and adjacent host cortex stimulation were mediated by glutamic acid acting on non-NMDA and NMDA receptors, and were modulated by both cholinergic and GABAergic drugs. In some cells, supra-threshold intra-transplant stimulation generated an epileptiform-like discharge, suggesting an imbalance between excitatory and inhibitory synapses. As expected, immunohistochemistry for cholinergic and GABAergic markers confirmed the electrophysiological results. Thus we show electrophysiological and immunohistochemical evidence supporting the functional development and integration of grafted cells into the host neocortex of adult animals.
\end{abstract}

Key words: adult rat; brain slices; electrophysiological recordings; homotopic graft

\section{Introduction}

A LTHOUGH TRANSPLANTATION OF NERVE CELLS has been used for many years to repair deficits that follow cerebral lesion, only in the last two decades has evidence emerged that many complex factors interact between the host and transplanted cells to ameliorate lesion symptoms. One of these factors, considered essential by many researchers, is the formation of connections between the host and transplanted tissue. Classically, it has been reported that functional success for frontal cortical transplant following motor cortex lesion depends on trophic action on the host brain and reconstruction of cortical circuitry, which improves the performance of animals in behavioral tests like the T-maze (Labbe et al., 1983; Roger and Ebrahimi-Gaillard, 1994). Moreover, it has been shown that a lesion in the rat frontal cortex produces a deficit in the paw used in reaching tasks (Plumet et al., 1991; Plumet et al., 1993). Such a deficit can be reduced by homotopic embryonic graft in both neonatal and adult rats. Furthermore, we have found (Riolobos et al., 2001) that embryonic frontal cortex transplanted into motor cortex in adult rats ameliorates the impairment in a paw-reaching-for-food task produced by lesions in this brain area. In these experiments a dense array of fibers was found between the transplant and the adjacent host cortex.

In other studies, transplanted cells have been reported to be metabolically active, integrated, and topographically organized within the host cortex (Grabowski et al., 1993; EbrahimiGaillard et al., 1995; Gaillard et al., 1998).

Electrophysiological transplant integration of fetal tissue has been studied in vivo by extracellular recordings in grafted rats, suggesting that restoration of some kind of capability to evoke synaptic potentials is needed for such integration $(\mathrm{Xu}$ et al., 1991; Chen et al., 2002). It is thought that functional improvement of transplanted tissue is time-dependent and appears between 45 and 60 days in adult rats, which is sufficient time for the establishment of anatomical graft-host connections (Fernandez-Ruiz et al., 1991; Plumet et al., 1991; 
Miranda et al., 1997). Hence these studies suggest that recovery requires a functional integration of the transplanted embryonic tissue into the host, with the presence of connections between the grafted tissue and the host brain.

Nevertheless, the electrophysiological properties of the transplanted neurons and the intra-transplant and transplanthost brain connections in adult animals have yet to be elucidated. In the present study we address these issues by carrying out both sharp electrode analysis and whole-cell recordings to study implanted neurons 3 months after transplantation, a period reported to be effective for host recovery (Kolb et al., 1988; Stein et al., 1988; Riolobos et al., 2001). We show the firing patterns and synaptic properties of neurons within grafts in frontal cortex slices. These results, also supported by immunohistochemical data, demonstrate that the transplanted embryonic tissue can be functionally integrated into the host.

\section{Methods}

Animals

All experiments in this study were carried out in accordance with the animal care guidelines of the European Communities Council (86/609/ECC), and every effort was made to minimize the suffering and number of animals used. Fifty male Wistar rats (Criffa Laboratories, Barcelona, Spain) were used, aged 3 months on delivery. They were housed, two per cage, under natural light/dark conditions at a temperature of $18-20^{\circ} \mathrm{C}$. Water and food were available ad libitum.

\section{Cortical lesion}

All surgical procedures were performed under anesthesia with $20 \mathrm{mg} / \mathrm{kg}$ Equithesin (injected IP). The animals $(\mathrm{n}=50)$ were unilaterally lesioned in the motor cortex. The lesion was made by aspiration as previously described in detail elsewhere (Riolobos et al., 2001). Briefly, deeply anesthetized animals were placed in a stereotaxic apparatus and the skull exposed at the level of the bregma. The animals were lesioned at the coordinates indicated by Neafsey and associates (1986) to remove the forelimb area of the motor cortex: anteroposterior 1-4 mm anterior to the bregma; lateral $1-3.5 \mathrm{~mm}$ right or left laterally to the midline; and dorsoventral the ventral limit of the lesion was the white matter underlying the cortex.

\section{Transplantation}

Seven days after lesioning the animals were subjected to unilateral transplantation. The donor tissue was obtained from 16-day-old rat embryos. Transplantation techniques were performed as previously described (Riolobos et al., 2001). Briefly, the pregnant rat was anesthetized with Equithesin and the embryos removed one at a time as needed. The donor's skull was cut at the midline and peeled back, the brain was dissected out, and the meninges were removed and placed in a dish with sterile glucose saline. Donor fetal tissue was set up while the host was being prepared to receive it. Two solid pieces of the fetal frontal cortex of approximately $1 \mathrm{~mm}^{2}$ each, including the total thickness of the cortex, were taken from the embryo and positioned at the bottom of the single motor cortex cavity in the host animal (Fig. 1A-C). The cavity containing the transplant was filled with a piece of gelfoam soaked in glucose-saline and the skin sutured. Pregnant rats were sacrificed by anaesthetic overdose.

\section{Slice preparation}

Three months after transplantation the grafted rats (postnatal days $\geq 180$ ) were processed to study the electrophysiological characteristics of the transplanted neurons in vitro $(n=38)$. The rats were deeply anesthetized with halothane gas, decapitated, and coronal slices ( $350 \mu \mathrm{m}$ thick) containing the transplanted tissue were obtained as described previously (Yajeya et al., 2000). Briefly, slices were kept for at least $1 \mathrm{~h}$ at room temperature in aerated $\left(95 \% \mathrm{O}_{2}+5 \% \mathrm{CO}_{2}\right)$ artificial cerebrospinal fluid (ACSF) before use. The ACSF was composed of $117 \mathrm{mM} \mathrm{NaCl}, 4.7 \mathrm{mM} \mathrm{KCl}, 2.5 \mathrm{mM} \mathrm{CaCl}_{2}, 1.2 \mathrm{mM}$ $\mathrm{MgCl}_{2}, 25 \mathrm{mM} \mathrm{NaHCO}, 1.2 \mathrm{mM} \mathrm{NaHPO}$, and $11 \mathrm{mM}$ glucose (pH 7.3, 310-315 mOsm). For recordings, the slices were transferred to an interface-type chamber and continuously perfused with aerated ACSF.

\section{Electrophysiological recordings}

The transplant was composed of cell clusters separated by bundles of fibers (Fig. 1D). The recordings were made in these cell clusters distributed throughout the transplant. In the adjacent host cortex, recordings were made close to the transplant.

For firing properties studies, sharp electrode recordings were made (140-180 M $\Omega$ ) by filling a pipette with $3 \mathrm{M}$ potassium acetate and connecting it to an intracellular recording amplifier (VF180; Biologic, Claix, France). The neurons were characterized by supra-threshold depolarizing current pulses according to their firing pattern. No characterization of host neurons was made, as this was not the aim of this study.

In order to morphologically identify the neurons and recording sites in the grafts (Fig. 1E), at the end of electrophysiological recording some neurons $(n=6)$ were filled with biocytin $(2 \%)$ in a potassium acetate solution (2M). Positive current pulses of $0.2 \mathrm{nA}$, with a duty cycle $(6 \mathrm{~min})$ of $300 \mathrm{~ms}$ on/300 ms off, were used. After injection, the slices were transferred to an incubation chamber for $30 \mathrm{~min}$ and then fixed by immersion in $0.1 \mathrm{M}$ phosphate buffer (PB) with $1.25 \%$ glutaraldehyde for $35 \mathrm{~min}$. The fixed slices were placed in a $2 \%$ agar solution, cryoprotected in $30 \%$ sucrose in $\mathrm{PB}$, and sections $(45 \mu \mathrm{m})$ were cut using a freezing microtome (HM400R; Microm, Heidelberg, Germany). The sections were collected in $\mathrm{PB}$, rinsed three times in the same buffer, and then incubated with avidin-biotin-peroxidase complex (Vector Laboratories, Burlingame, CA) for $3 \mathrm{~h}$ at room temperature. For visualization of the biocytin, 3,3'-diaminobenzidine was used as chromogen. The reaction was intensified with nickel ammonium sulfate. The sections were counterstained with cresyl violet to determine the position of the filled neuron in the graft. Neurons were reconstructed from serial sections. Drawings were made using a camera lucida (Labophot; Nikon, Kawasaki, Japan) for all sections that contained a part of the reconstructed neuron.

For connectivity studies, whole cell path-clamp recordings were mainly used. They were performed at room temperature at a holding potential of $-70 \mathrm{mV}$. Evoked postsynaptic currents were elicited by intra-transplant or adjacent host cortex stimulation applied through a bipolar electrode (WPI TM33B10 with $1 \mathrm{M} \Omega$ of nominal impedance) connected to a programmable stimulator (Biologic SMP-311; Biologic) to 

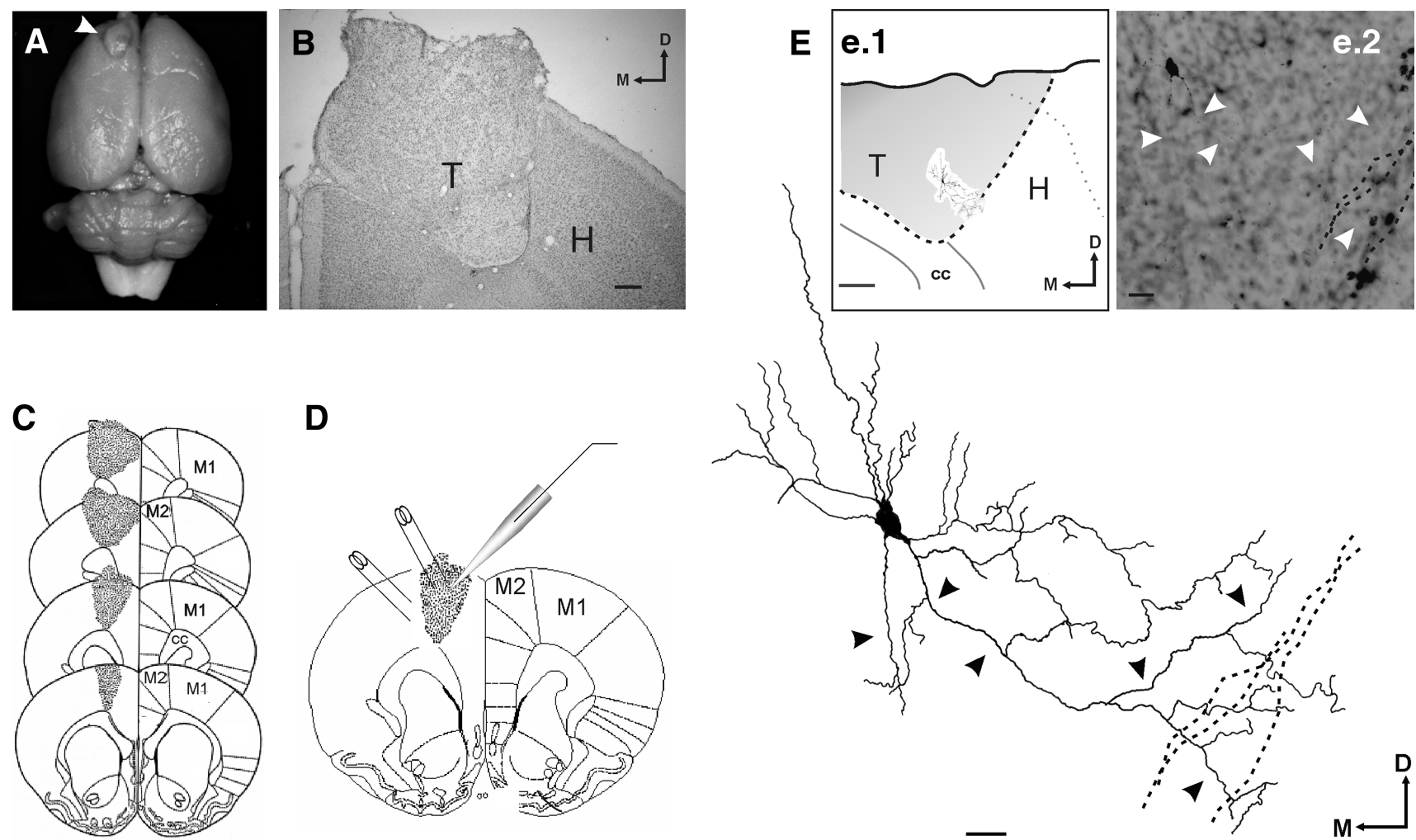

FIG. 1. Experimental design: stimulation and recording sites in the grafted tissue. (A) Photograph of a transplanted rat brain. The arrowhead indicates the homotopic cortical graft. (B) Photomicrograph of a coronal section through a homotopic transplant stained with cresyl violet ( $\mathrm{T}$, transplant; $\mathrm{H}$, host; scale bar $300(\mu \mathrm{m})$. (C) Serial coronal sections showing the graft (CC, corpus callosum; M1, primary motor cortex; M2, secondary motor cortex). (D) Schematic representation showing the recording and stimulus electrode locations in a coronal section through the graft. Recordings were made using current clamp or patch-clamp techniques. The stimuli were applied intra-transplant or to the adjacent host cortex (modified from Paxinos and Watson, 1998). (E) Drawing showing the reconstruction of the neuron after an intracellular recording. Note arrowheads showing neural processes crossing through the transplant edge and reaching adjacent motor cortex. Dashed lines indicate the graft-host interface. Insets: (e.1) Schematic drawing of the location in the transplant of the same neuron labeled with biocytin after intracellular recording. (e.2) A photomicrograph of a 45- $\mu \mathrm{m}$-thick slice partially showing the neuron illustrated in $\mathrm{E}$ (scale bars: e.1, $1 \mathrm{~mm}$; e.2 and E, $100 \mu \mathrm{m}$; CC, corpus callosum; T, transplant; H, host; M, medial; D, dorsal).

generate single square-wave pulses of $100 \mu$ s duration and $100-500 \mu \mathrm{A}$ intensity. Patch pipettes (5-10 M $\Omega$ ) filled with $117.5 \mathrm{mM}$ K-gluconate, $21.5 \mathrm{mM} \mathrm{KOOCCH}, 4 \mathrm{mM} \mathrm{NaCl}$, $10 \mathrm{mM}$ HEPES, $0.2 \mathrm{mM}$ EGTA, $6 \mathrm{mM} \mathrm{Na} \mathrm{N}_{2} \mathrm{ATP}, 0.3 \mathrm{mM}$ $\mathrm{Na}_{3} \mathrm{GTP}, 2 \mathrm{mM} \mathrm{MgCl}$ (pH 7.2-7.3, 300-320 mOsm), were connected to a patch-clamp amplifier (Biologic RK 400; Biologic). Postsynaptic potentials were characterized according to their amplitude (as a function of the resting potential) and latency. A schematic representation of a graft showing the recording and stimulating electrode locations are represented in Fig. 1D.

\section{Data analysis}

Sharp electrode data were acquired online with the help of a CED 1401 interface (CED, Cambridge, UK), whereas patchclamp recordings were acquired through an analog-to-digital interface (DTR-GPIB; Biologic), both sets of data were stored on a personal computer (sample frequency $12.5 \mathrm{kHz}$ ). All recorded currents were low-pass filtered with a cutoff frequency of $2 \mathrm{kHz}$. No compensation of capacitive transients and series resistance was performed during recordings of synaptic events. Analyses in both cases were performed using the MiniAnalysis Program, version 6.0.3 (Synaptosoft, Decatur, GA).

\section{Chemicals}

Drugs were applied using a gravity-fed system and added to the bath solution from previously prepared stock solutions stored at $-20^{\circ} \mathrm{C}$. Bicuculline (Tocris, Madrid, Spain) was applied to determine the presence of functional inhibitory $\gamma$-aminobutyric acid type $\mathrm{A}\left(\mathrm{GABA}_{\mathrm{A}}\right)$ receptors in the preparation, and 6-cyano-7-nitroquinoxaline-2,3-dione (CNQX) and amino-5-phosphonopentanoate (APV) (Tocris) were added to characterize the excitatory glutamatergic responses. Carbachol, a cholinergic agonist, and atropine sulfate, a muscarinic antagonist (Sigma, Poole, UK), were used to assess the presence of functional cholinergic receptors. Finally, nifedipine and $\omega$-agatoxin IVA (Peninsula Lab., Belmont, CA), were used to block different types of voltage-dependent calcium channels.

\section{Immunocytochemistry and histology}

In some animals $(n=9)$ the presence of choline acetyltransferase (ChAT) and glutamic acid decarboxylase (GAD), as well as $\mathrm{GABA}_{\mathrm{A}}$ and muscarinic acetylcholine $\mathrm{M}_{1}$ receptors in the grafted neurons were investigated. Deeply anesthetized animals were perfused through the ascending aorta with a 
wash solution composed of $2 \%$ dextran in $\mathrm{PB}, \mathrm{pH} 7.4$ at room temperature. This was followed by $500 \mathrm{~mL}$ of $4 \%$ paraformaldehyde (for ChAT), $4 \%$ paraformaldehyde $/ 0.1 \%$ glutaraldehyde (for GAD), or $2 \%$ paraformaldehyde $/ 2 \%$ glutaraldehyde (for $\mathrm{GABA}_{\mathrm{A}}$ and $\mathrm{M}_{1}$ receptors) in $\mathrm{PB}$. After perfusion, the brains were removed from the skulls and postfixed in the same fixative overnight at $4^{\circ} \mathrm{C}$. Coronal sections cut on a vibratome or a freezing microtome at $40 \mu \mathrm{m}$ were processed for ChAT, GAD, $\mathrm{GABA}_{\mathrm{A}}$, or $\mathrm{M}_{1}$ receptors using the avidin-biotin procedure (Vector Laboratories). Sections were incubated overnight at $4{ }^{\circ} \mathrm{C}$ in anti-ChAT monoclonal antibody (MAB5270 diluted 1:500; Chemicon, Billerica, MA), antiGAD serum (AB5992 diluted 1:2000; Chemicon), anti-GABA receptor, $\beta$-chain monoclonal antibody (MAB341 diluted 1:1000; Chemicon), or anti-muscarinic acetylcholine $\left(\mathrm{M}_{1}\right)$ antibody receptor serum (M9808 diluted 1:200; Sigma). Six to 12 sections were analyzed per animal/antibody. Control sections were always processed without the primary antibody.

In some animals $(n=3)$ the morphological characteristics of the graft tissue were studied. Anesthetized animals were perfused with saline followed by $10 \%$ formalin in $\mathrm{PB}(\mathrm{pH} 7.4)$. The brains were removed and post-fixed in fresh fixative at $4{ }^{\circ} \mathrm{C}$ for $3 \mathrm{~h}$. They were then soaked in $30 \%$ sucrose in PB for cryoprotection. Coronal sections $50 \mu \mathrm{m}$ thick were cut on a freezing microtome. The sections were mounted on gelatincoated slides and stained with cresyl violet for Nissl substance.

\section{Statistics}

Unless otherwise indicated the electrophysiological data are always expressed as the mean \pm SEM. In all cases " $n$ " represents the average number of neurons. Unless otherwise indicated action potentials and synaptic currents were averaged (five or more) before quantitative analysis. Statistical analysis of the data collected was performed using a paired Student's $t$-test, and when necessary by ANOVA test. Statistical significance was set at $p \leq 0.05$.

\section{Results}

\section{Firing properties of transplanted cells}

To examine the electrophysiological properties of the transplanted neurons, intracellular recordings with sharp electrodes $(n=20)$ were obtained from cells in the graft. They did not present spontaneous action potentials at resting membrane potential (RMP) values $(-69 \pm 2 \mathrm{mV})$. The direct activation of these neurons by supra-threshold depolarizing current injection (0.1-0.5 nA) defined two main patterns of discharge: regular firing $(\mathrm{n}=12$, Fig. $2 \mathrm{~A})$ and burst firing $(\mathrm{n}=8$, Fig. 2B).
Regular firing neurons presented action potentials or a train of spikes with very slow adaptation (Fig. 2A). RMP was $-71.4 \pm 1.9 \mathrm{mV}$, input resistance of the neurons was $132.1 \pm$ $18.5 \mathrm{M} \Omega$, the mean membrane time constant was $13.6 \pm 3.4$ $\mathrm{msec}$, and the threshold potential was $-47.9 \pm 1.8 \mathrm{mV}$. The spike amplitude was $67.9 \pm 3.5 \mathrm{mV}$, with a duration of $1.6 \pm$ $0.3 \mathrm{msec}$, a rise time of $0.25 \pm 0.02 \mathrm{msec}$, a decay time of $0.59 \pm 0.2 \mathrm{msec}$, and a half width of $0.89 \pm 0.2 \mathrm{msec}$.

Burst-firing cells responded with consecutive action potentials (bursts) to the depolarizing pulse (Fig. 2B) The mean $\mathrm{RMP}$ was $-66.1 \pm 2.2 \mathrm{mV}$ and the mean input resistance of the neurons was $153.4 \pm 10.4 \mathrm{M} \Omega$ with a membrane time constant value of $6.5 \pm 1.4 \mathrm{msec}$. The threshold potential was $-45.2 \pm$ $2.1 \mathrm{mV}$ and the spike amplitude was $56.5 \pm 3.4 \mathrm{mV}$, with a duration of $2.4 \pm 0.3 \mathrm{msec}$, a rise time of $0.31 \pm 0.05 \mathrm{msec}$, a decay time of $0.52 \pm 0.08 \mathrm{msec}$, and a half width of $0.82 \pm$ $0.13 \mathrm{msec}$.

These electrophysiological patterns of transplanted neurons are similar to those reported for some of the cellular types described in normal rat motor cortex (Degenetais et al., 2002). According to these results, fetal transplanted neurons were differentiated into at least two electrophysiological-firingtypes: regular spiking and burst firing.

\section{Intra-transplant evoked synaptic responses}

In order to investigate the synaptic evoked responses on neurons in the graft, intra-transplant electrical stimulation was applied at subthreshold values. The synaptic responses evoked were recorded by using whole cell patch clamp $(n=12)$ or sharp electrodes $(n=10)$, and consisted of excitatory postsynaptic responses in all cases. This response showed a graded amplitude nature, depending on stimulus intensity (Fig. 2C) and membrane potential (Fig. 2D), suggesting a monosynaptic nature. They had a mean amplitude of $29.5 \pm 1.9 \mathrm{pA}$, a mean latency of $2.1 \pm 0.3 \mathrm{msec}$, a duration of $28.8 \pm 20.6 \mathrm{msec}$, a rise time of $8.1 \pm 3.2 \mathrm{msec}$, a decay time of $18.5 \pm 9.8 \mathrm{msec}$, and a half width of $21.2 \pm 9.2 \mathrm{msec}$ (Fig. 2C and D).

In patch-clamp recorded neurons $(n=12)$ the evoked excitatory postsynaptic currents (EPSCs) displayed a rectifying voltage-current relationship that could be observed by changing the holding potential from -70 to $+40 \mathrm{mV}$, with a reversal potential between -10 and $0 \mathrm{mV}$ (Fig. 2D).

On the other hand, in $73 \%$ of the recorded cells the evoked responses consisted of excitatory postsynaptic potentials (EPSPs) that generated a single action potential when a sole stimulus reached suprathreshold (Fig. 2C). In the remaining $27 \%$ an epileptiform-like discharge (paroxysmal depolarization shift, PDS) was evoked (Fig. 3) instead of a single

FIG. 2. Electrophysiological properties of neurons in the graft. (A and B) Current clamp responses of transplanted neurons recorded using sharp electrodes during injection of supra-threshold depolarizing current pulses. We identified two types of neurons according to their firing patterns: regular (A) and burst (B) neurons. Current-voltage (I-V) behavior showed a linear voltage-current relationship for regular neurons, whereas burst neurons showed marked rectifying at more positive current intensity values. (C and D) Evoked response obtained in a transplanted cell by intra-transplant stimulation. (C) Excitatory postsynaptic response evoked under current-clamp mode. Note that EPSP amplitude was graded and supra-threshold stimulation generated an action potential. The graph on the right shows the relationship between stimulus intensity and excitatory postsynaptic potential (EPSP) amplitude. (D) Under voltage clamp, excitatory postsynaptic currents (EPSC) response changed from inward to outward in relation to voltage. I-V relationship recorded at different holding potentials, ranging from -70 to $40 \mathrm{mV}$, showed a reversal potential around $-10 \mathrm{mV}$. The graph on the right shows the relationship between current and holding membrane potential. Note that synaptic response displayed a rectifying voltage-current relationship. 


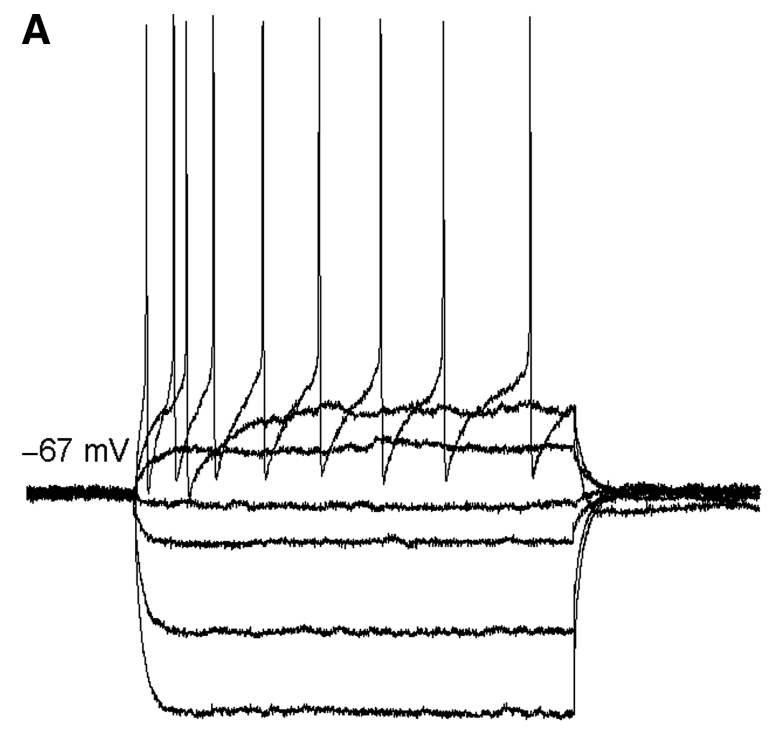

B
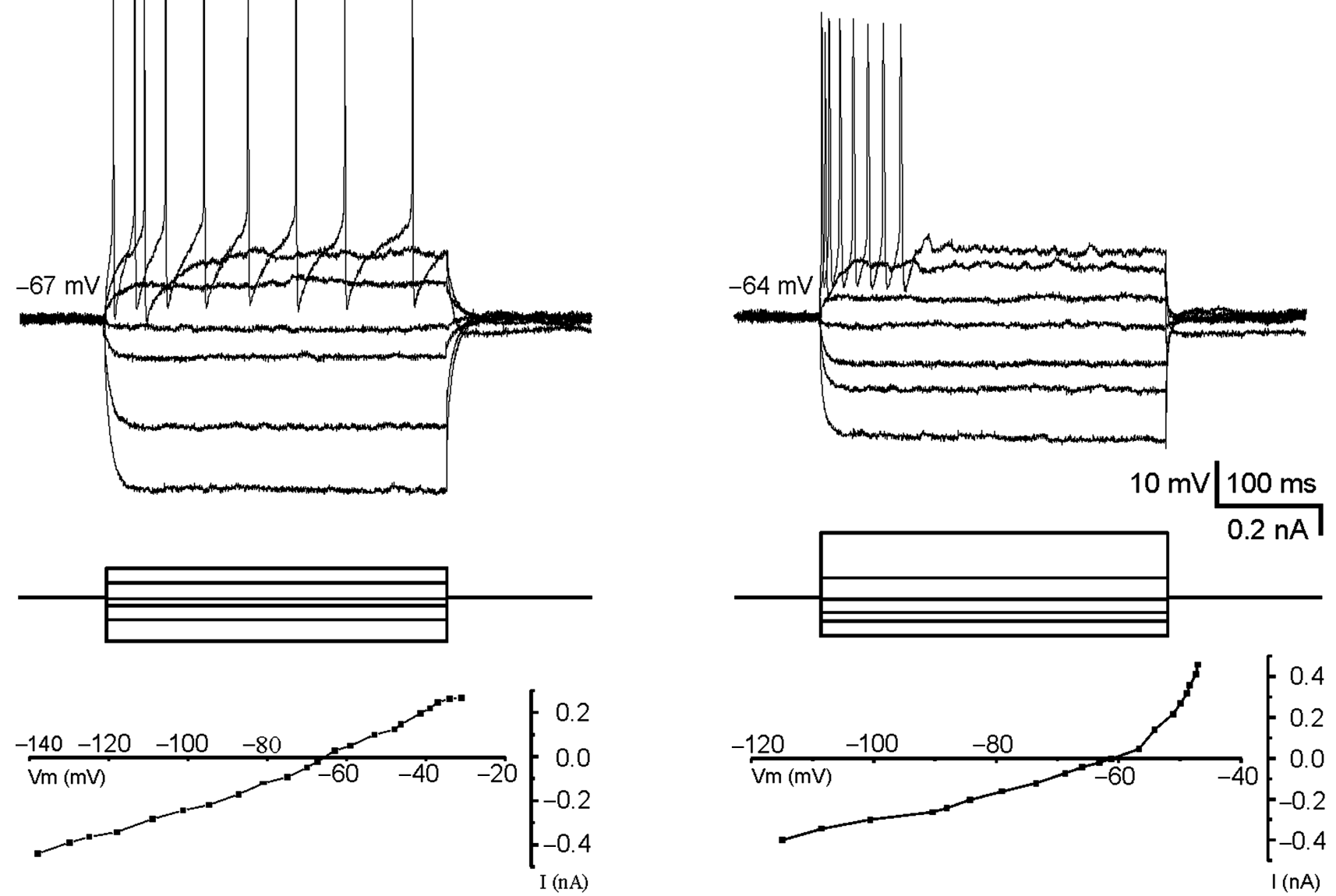

C
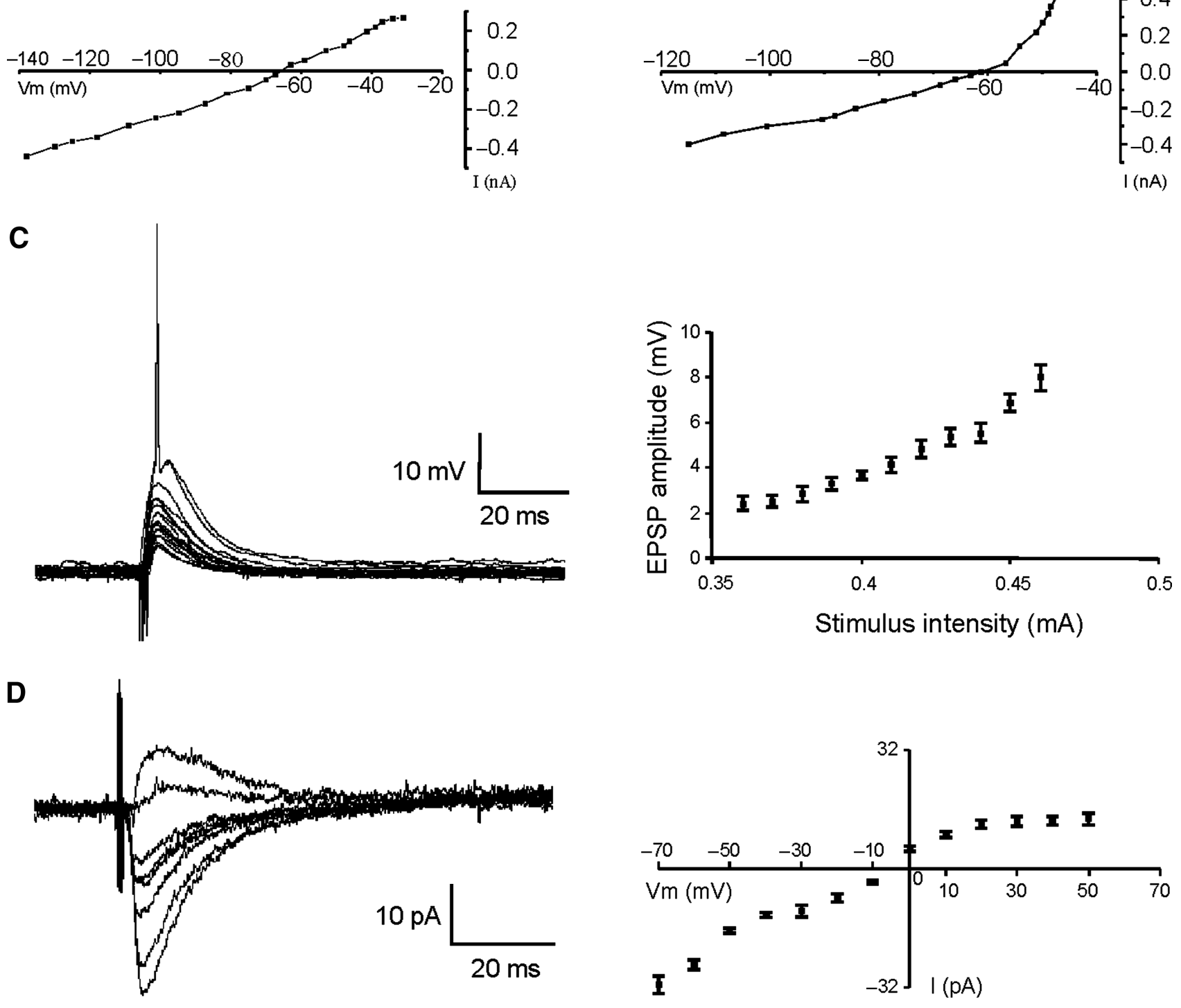
action potential. This response consisted of a long depolarization $(0.9 \pm 0.5 \mathrm{sec})$ with a variable number of superimposed action potentials, regardless of prior direct current (DC) injection (Fig. 3A, C.3, and D). The evoked epileptiform-like response was always generated by intra-transplant stimulation and never by intracellular stimulus or by adjacent host cortex stimulation (even when a high-frequency stimulus of $200 \mathrm{~Hz}$ and $100 \mathrm{msec}$ was applied; Fig. 4E), suggesting that its substrates are the circuits formed in the transplanted tissue.

\section{Connections between the transplant and adjacent host cortex}

Connections between adjacent host cortex and neurons in the graft were also explored (Fig. 4B-E). Stimulus applied in the host cortex $(n=9) 1 \mathrm{~mm}$ from the limit of the transplant, evoked postsynaptic responses that were always excitatory in $33 \%$ of the cases, showing successful afferent neurotransmission of transplanted neurons. The synaptic responses (Fig. 4B) had a mean latency of $1.46 \pm 0.8 \mathrm{msec}$, a duration of $45.4 \pm 8.9 \mathrm{msec}$, a rise time of $2.8 \pm 0.6 \mathrm{msec}$, a decay time of $7.5 \pm 1.3 \mathrm{msec}$, and a half width of $9.92 \pm 1.8 \mathrm{msec}$. The amplitude also showed a graded nature, depending on stimulus intensity and on RMP (data not shown). Moreover, as shown in Figure $4 \mathrm{E}$, train stimulation $(200 \mathrm{~Hz}$ for $100 \mathrm{msec})$ of the adjacent cortex evoked a sustained depolarization of neurons recorded in the graft exceeding the end of the train by hundreds of milliseconds (amplitude of $15.8 \pm 0.4 \mathrm{mV}$ and a duration of $678.7 \pm 83.1 \mathrm{msec}$ ), without any evident change in latency, suggesting its monosynaptic nature.

Finally, to characterize efferent synaptic signals from graft neurons to adjacent cortex, neurons in this latter area were recorded $(n=6)$. The graft region was electrically stimulated at subthreshold values and an excitatory synaptic response could be evoked (amplitude $7.35 \pm 0.53$, latency $1.6 \pm 0.1$ $\mathrm{msec}$, a duration of $19.4 \pm 2.9 \mathrm{msec}$, a rise time of $1.2 \pm 0.1$ msec, a decay time of $5.5 \pm 0.3 \mathrm{msec}$, and a half width of $7.9 \pm 0.4 \mathrm{msec} ; \mathrm{n}=1$ ) (Fig. $4 \mathrm{C}$ ).

Some neurons in the graft $(n=6)$ were iontophoretically injected with biocytin following electrophysiological recording with sharp electrodes. In some cases $(n=3)$ reconstruction of stained neurons allowed us to identify neuronal processes growing for hundreds of microns into the grafted tissue (Fig. $1 \mathrm{E})$. Some of them could also be followed crossing the transplant limits into the adjacent motor cortex, supporting the existence of graft-host brain connections (Fig. 1E).

\section{Synaptic transmission in the graft}

In order to characterize neurotransmitters mediating the intra-transplant synaptic responses, we performed different pharmacological interventions. As shown in Figure 5, the EPSCs evoked by subthreshold electrical pulses applied intratransplant (Fig. 5A) were only modified in duration by slice superfusion with APV $(50 \mu \mathrm{M})$ (Fig. 5B; decay time: control: $9.42 \pm 0.52 \mathrm{msec}$; versus APV: $6.59 \pm 0.47 \mathrm{msec} ; p<0.05$, $\mathrm{n}=5)$, but were completely removed by the application of CNQX $(10 \mu \mathrm{M})$ (Fig. 5C). These results indicate that the EPSC evoked in neurons by intra-transplant stimulation was essentially mediated by glutamate acting on both NMDA and AMPA-kainate receptors. In addition, perfusion with CNQX $(10 \mu \mathrm{M})$ plus APV $(50 \mu \mathrm{M})$ also blocked the PDS response without affecting the capability of the cell to generate action potentials $(n=5$; Fig. 6 C). This effect suggests that the PDS response is not dependent on the intrinsic membrane properties of the transplanted cells, but depends on glutamatergic synaptic activity evoked by intra-transplant stimulation (Fig. 6). What is more, the fact that PDS was not affected by perfusion with nifedipine $(5 \mu \mathrm{M})(\mathrm{n}=3)$ or $\omega$-agatoxin IVA $(100 \mathrm{nM})(\mathrm{n}=3)$ (data not shown) suggests its independence from calcium entering through voltage-dependent calcium channels.

On the other hand, even when inhibitory postsynaptic currents were never elicited in the transplanted cells by extracellular stimulation, the application of bicuculline $(10 \mu \mathrm{M})$ $(\mathrm{n}=7)$ induced an increase in EPSC amplitude (control: $16.33 \pm 0.86 \mathrm{pA}$; bicuculline: $19.17 \pm 1.37 \mathrm{pA} ; p<0.05$ ) (Fig. 7A). In two out of seven recorded neurons treated with bicuculline, blocking GABAergic receptors induced a prolonged EPSC current, presumably mediated through activation of polysynaptic pathways (Fig. 7B). Taken together these results suggest that cells composing the transplant expressed functional GABAergic receptors.

In order to investigate whether the responses evoked on grafted neurons could be modulated by cholinergic drugs, carbachol and atropine were used. Superfusion of the slice with the cholinergic agonist carbachol $(5 \mu \mathrm{M})$ was able to induce a slow-building and long-lasting depolarization of membrane potential $(4.2 \pm 0.31 \mathrm{mV} ; \mathrm{n}=5)$ in the recorded neurons (Fig. 7C and D). In addition, the amplitude of the excitatory response holding the membrane potential at resting values was depressed significantly (control: $10.18 \pm 0.58 \mathrm{mV}$ versus carbachol: $4.89 \pm 0.31 \mathrm{mV} ; p<0.001$ ) (Fig. 7C). However, perfusion with the muscarinic antagonist atropine $(5 \mu \mathrm{M})(\mathrm{n}=5)$ did not generate significant changes in the EPSC amplitude (control: $23.4 \pm 0.86 \mathrm{pA}$; versus atropine: $22.4 \pm$ $0.83 \mathrm{pA}$ ) (data not shown). These results suggest the existence of cholinergic receptors in the graft with capacity to modulate the excitatory glutamatergic synaptic transmission, in spite of the graft not showing intrinsic cholinergic activity.

\section{Neurotransmitter and receptor immunocytochemistry}

All grafted animals presented surviving transplants, and the grafts were well embedded in the host cortical tissue. A photograph of a grafted brain is shown in Figure 1A. The cytoarchitectural features of the graft tissue were studied in sections stained with cresyl violet. In the Nissl-stained material all the transplants studied were seen to contain welldifferentiated neurons of normal appearance. The transplant was composed of cell clusters separated by bundles of fibers (Fig. 1B). The characteristic stratification of the normal host cortex was not preserved within the transplant. The transplant-host interface was generally obvious and characterized by the presence of fiber laminae surrounding the transplant (Fig. 1B).

Choline acetyltransferase immunolabeling was identified in a small number of transplanted cells. Choline acetyltransferase-immunoreactive cells showed bodies of different sizes and shapes, and in some neurons dendrites radiated from the cell bodies (Fig. 8A).

GAD immunopositivity was identified in some grafted cells across the transplant. The cell bodies of GADimmunoreactive cells tended to be rounded or pyramidal 
A

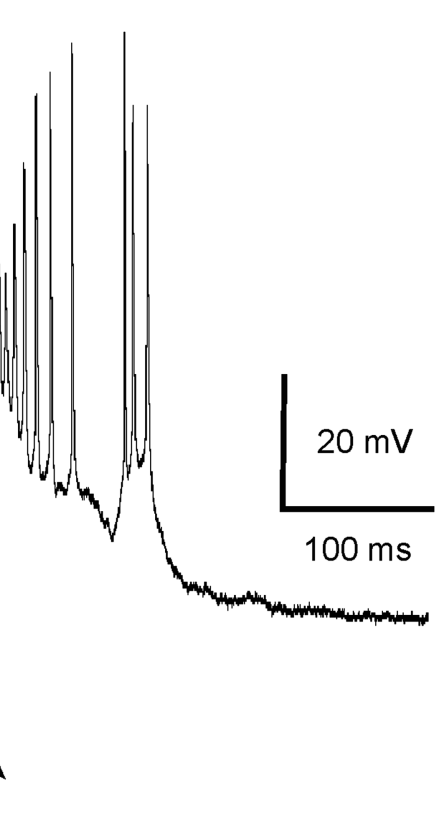

B

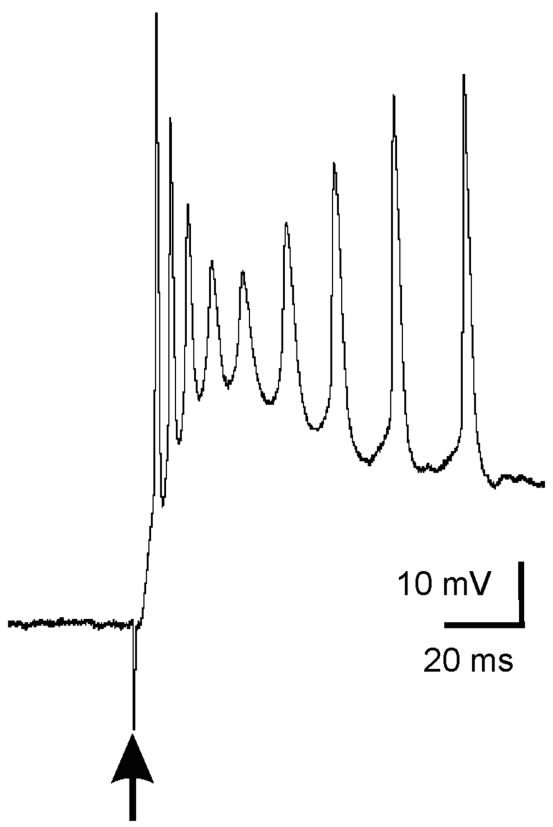

C.2
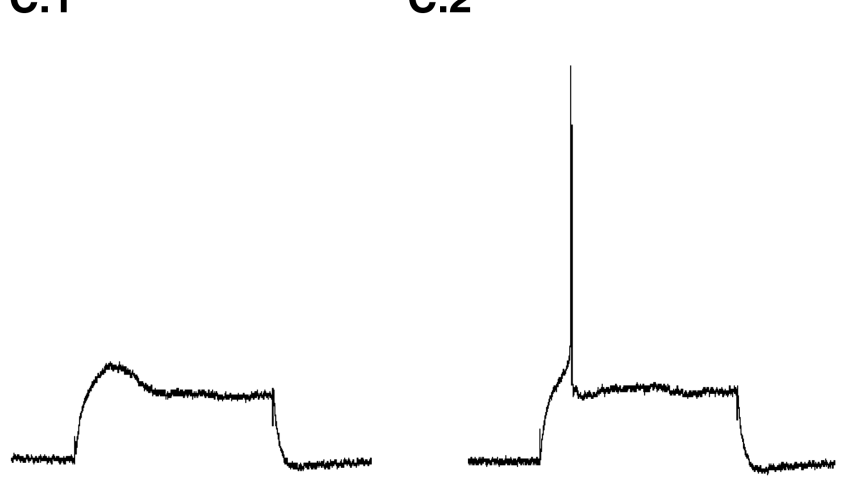

C.3
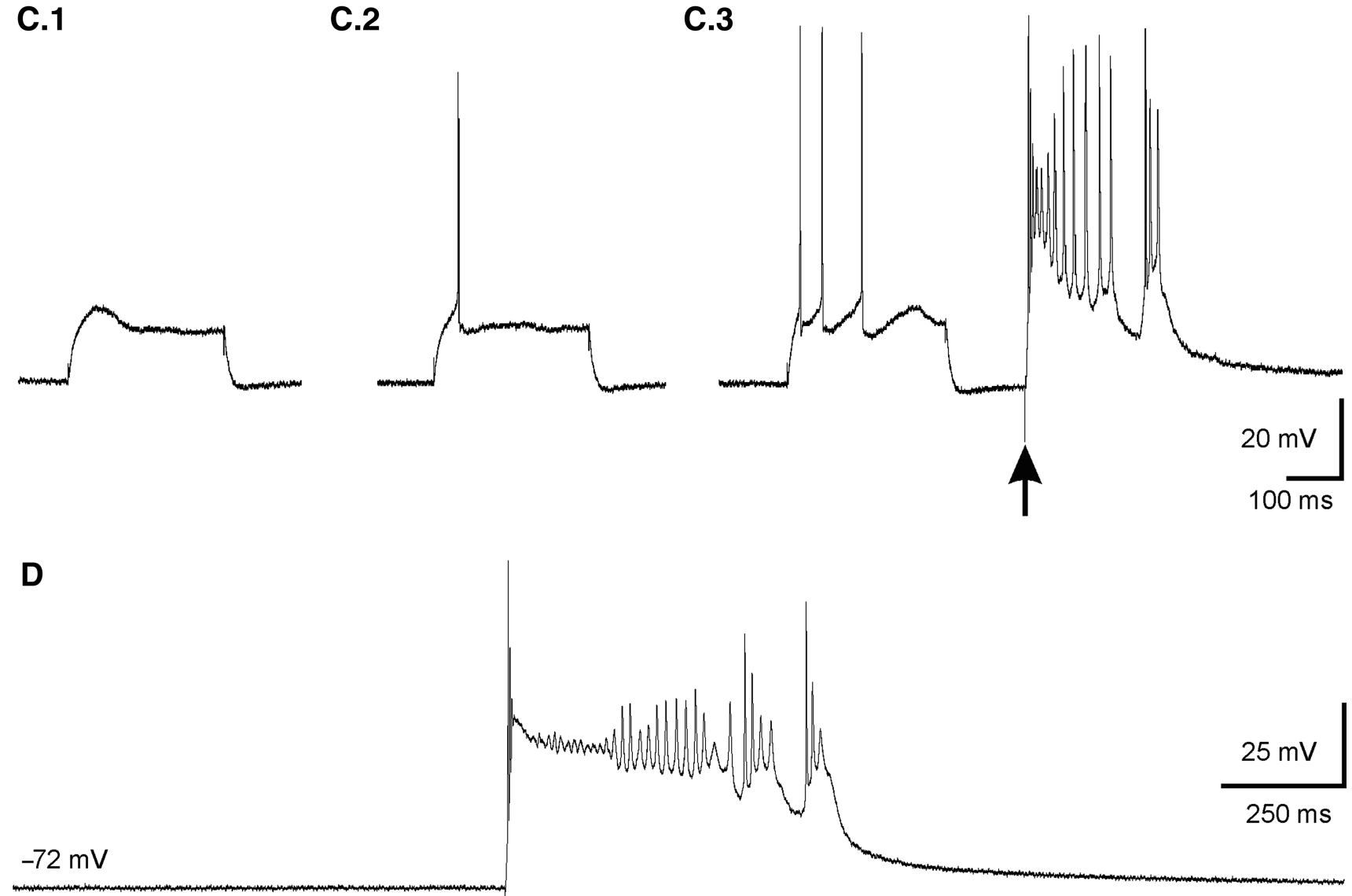

FIG. 3. Epileptiform-like response to supra-threshold intra-transplant stimulation (paroxysmal depolarization shift, PDS). (A) Response evoked by hyperpolarizing DC current followed by supra-threshold extracellular intra-transplant stimulation (arrow) under current-clamp mode. The RMP was $-69 \mathrm{mV}$. The evoked synaptic response showed an ascending phase followed by a repolarizing phase with discharge of multiple action potentials. (B) Trace of the same waveform at different voltage and time scales. (C) The same neuron responding to intracellular depolarizing DC pulses (traces C.1, C.2, and C.3). This neuron was characterized by regular firing. When a supra-threshold extracellular stimulation was applied, an epileptiform-like discharge was generated (C.3). (D) PDS evoked in a different cell without previous current injection. 
A Graft - Graft St.

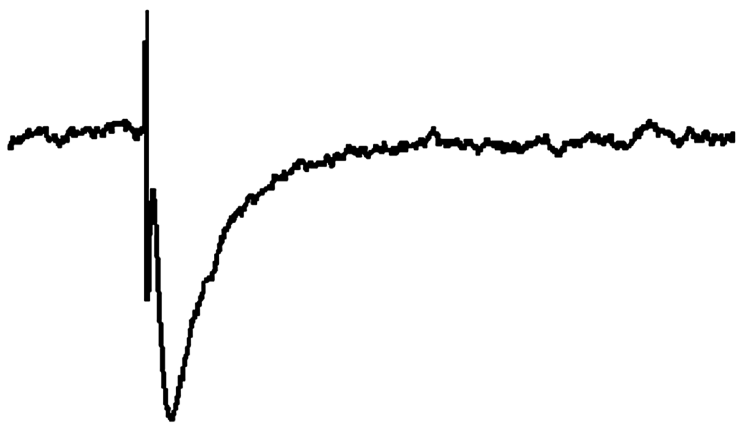

C

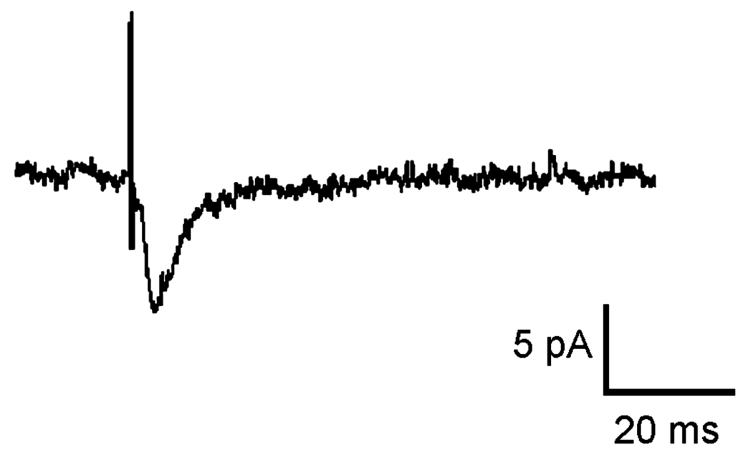

B Graft - Host St.

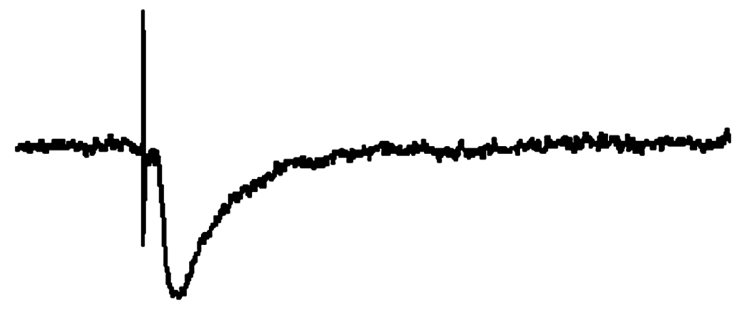

D Superimposed traces

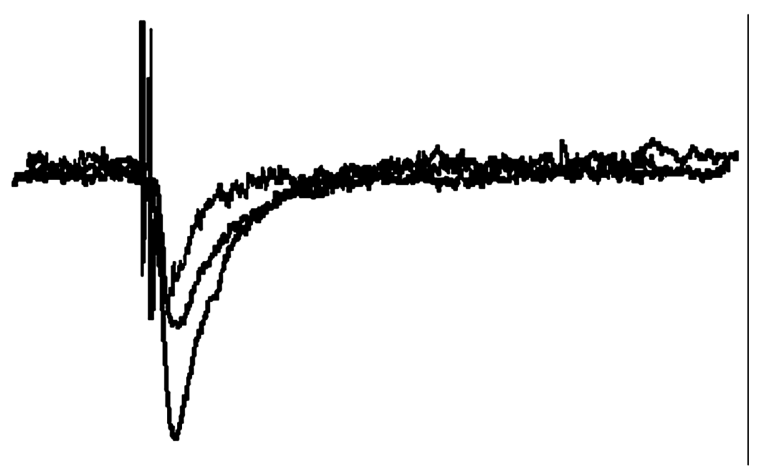

E

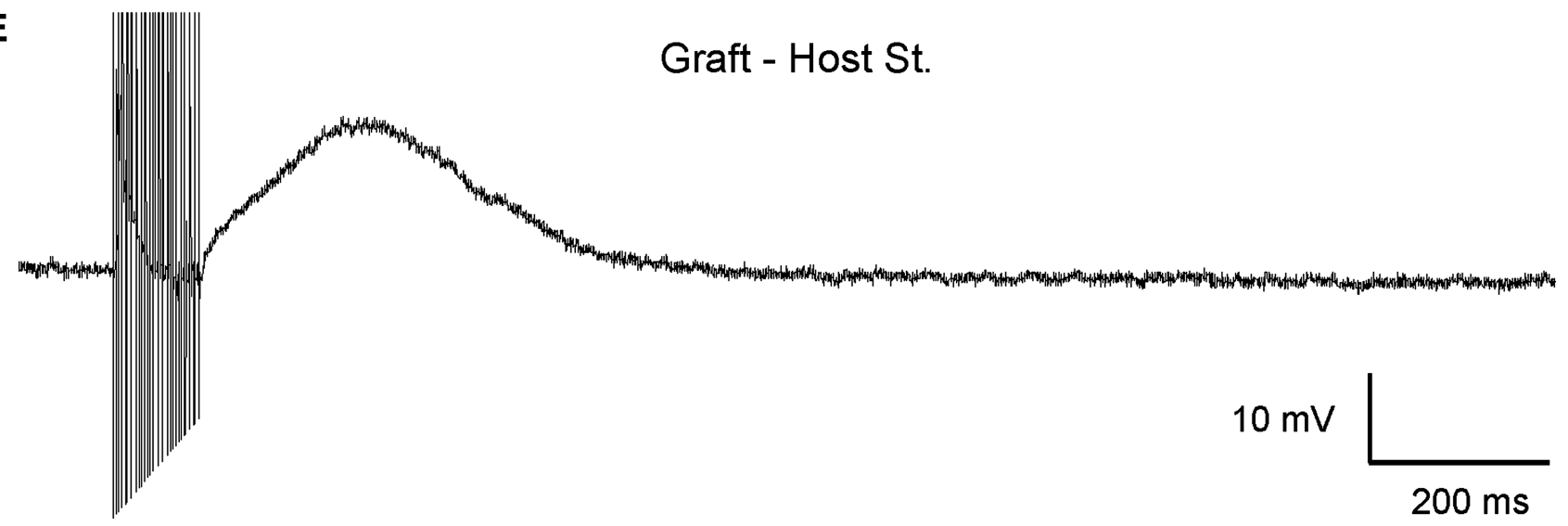

FIG. 4. Electrophysiological characterization of the connections between the transplant and the adjacent cortex. (A) Example of an evoked response in a transplanted neuron by transplant stimulation (mean amplitude $29.52 \pm 1.87 \mathrm{pA}$ ). (B) Graftevoked synaptic current by adjacent host cortex stimulation (mean amplitude $12.42 \pm 1.43 \mathrm{pA}$ ). (C) Example of an evoked response obtained in the adjacent host cortex by intra-transplant stimulation (mean amplitude $7.35 \pm .53 \mathrm{pA}$ ). (D) Superimposed traces. (E) Neuron recorded in the graft showing a sustained response to high-frequency stimulation of adjacent cortex. No PDS was observed in these conditions (St., stimulation).

(Fig. 8B). Immunopositive dendrites were not consistently exhibited, but were present in some cases.

$\mathrm{GABA}_{\mathrm{A}}$ receptor immunoreactivity was identified outlining the soma and processes of some grafted neurons (Fig. $8 \mathrm{C})$. Immunolabeling of muscarinic acetylcholine receptors $\left(\mathrm{M}_{1}\right.$; a widely expressed receptor in the normal cortex) was present surrounding the somata of some transplanted cells. Anti-M $\mathrm{M}_{1}$ antibody did not label the cell processes (Fig. 8D).

These results support the presence of GABAergic and cholinergic modulations of the glutamatergic neurotrans- mission as shown by the electrophysiological recordings carried out in the transplant.

\section{Discussion}

During the last century, many studies have shown the use of the grafting of tissue to the brain as a strategy to generate new neurons and glial cells capable of being integrated functionally during the repair process of the adult central nervous system (Bjorklund and Lindvall, 2000; Tuszynski, 
A Control

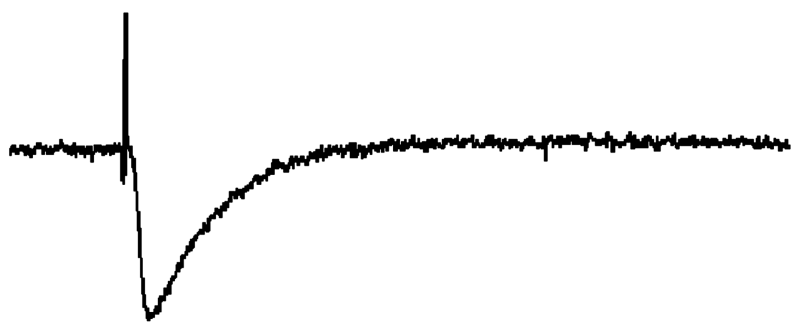

C $\quad \mathrm{APV}+\mathrm{CNQX}$

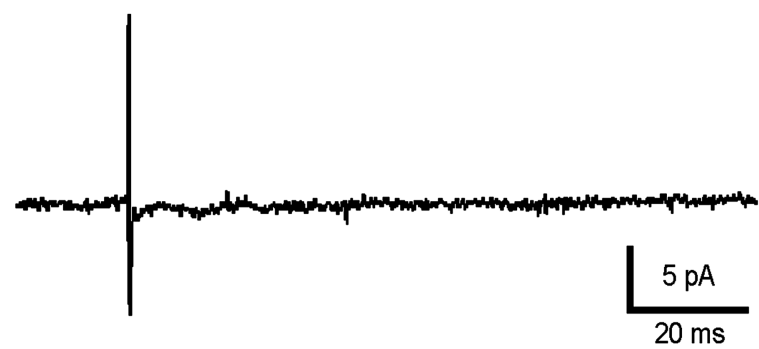

B APV

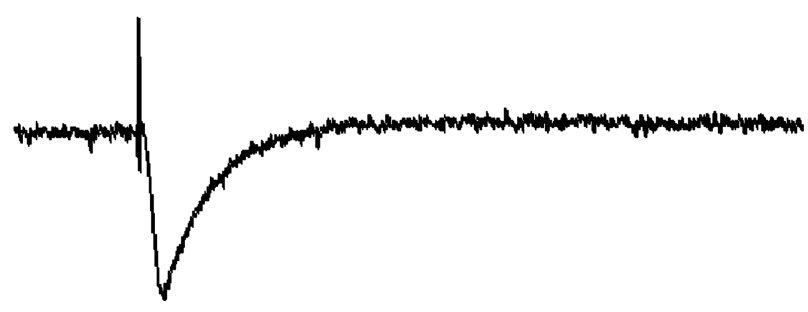

D Superimposed

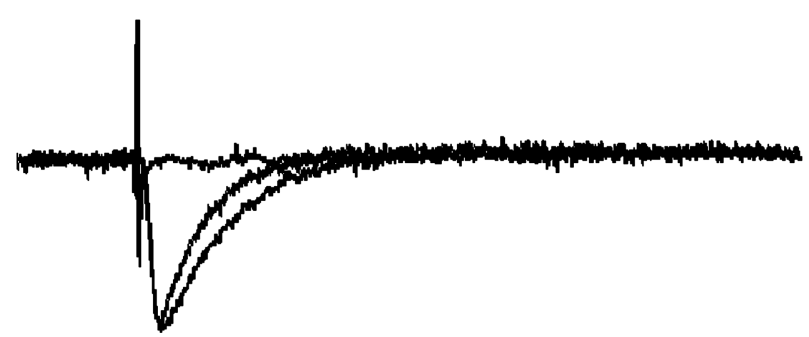

FIG. 5. Graft-evoked synaptic responses were mediated through glutamatergic receptors. (A) Postsynaptic currents recorded under voltage clamp $(-70 \mathrm{mV})$ by intra-transplant stimulation. The EPSC duration decreased during APV application $(\mathbf{B} ; p<0.05)$, and was blocked by addition of CNQX $(10 \mu \mathrm{M} ; \mathbf{C})$. (D) The three traces superimposed (the scale bar in C is the same as that for $\mathrm{A}, \mathrm{B}$, and D).

2007). Until now, cell survival, metabolism, and connections inside the graft and between graft and host have been demonstrated by glucose uptake (Ebrahimi-Gaillard et al., 1995), neurotracer injections (Heredia et al., 1991; Grabowski et al., 1993; Garnier et al., 1997; Riolobos et al., 2001), and recently by the use of green fluorescent protein expression (Englund et al., 2002; Alvarez-Dolado et al., 2006; Gaillard et al., 2007). The physiological properties of early grafted neurons in young animals have been reported, and show that these cells can be integrated into the very young brain and used to modify or repair neural circuits (Englund et al., 2002; Wernig et al., 2004; Alvarez-Dolado et al., 2006). Nevertheless, to our knowledge, these kinds of studies in adult brain have not been reported, either for neuronal properties or connectivity of the transplant. We have previously shown, by using fetal homotopic transplants in the motor cortex area, a functional graft-dependent recovery by using behavioral studies (Riolobos et al., 2001). Very recently it has been demonstrated that, at least for cortex, there is substantial anatomical reestablishment of cortical circuitry following embryonic cortex grafting into the adult brain (Gaillard et al., 2007). Here we investigate whether the integration of transplanted cells into adults develops not only functional synaptic connectivity with the host tissue, but also electrophysiological properties that are similar to neurons previously described in the neighbor host tissue (Kawaguchi, 1993).

Our results have shown that transplanted neurons have membrane properties and firing discharges similar to neurons from normal cortex previously described in vitro and in vivo (Kawaguchi, 1993; Degenetais et al., 2002). Current depolarization characterized two different firing patterns: regular and burst firing neurons. These cell types could not be differenti- ated from normal cortex neurons by their electrophysiological characteristics, such as RMP, spike amplitude, or input resistance. Regular-spiking and burst cells have been reported in the rat frontal cortex (Chagnac-Amitai et al., 1990). Moreover, cortical cells that show membrane-rectifying properties and all-or-nothing burst discharge to depolarizing current pulses are present in sensory-motor cortical slices (Connors et al., 1982; Degenetais et al., 2002; Cho et al., 2004). Differences displayed by regular-spiking and burst neurons in the current-voltage (I-V) relationship could be due to different expression of receptor populations (e.g., AMPA receptors). Recently it has been shown that an immune response from TNF- $\alpha$ after the trauma or transplantation might remodel the AMPA receptor population from GluR2-containing to GluR2lacking (Leonoudakis et al., 2008). This would likely change the I-V curve from linear to inwardly rectifying. Furthermore, regular-spiking and burst discharge action potentials generated by intracellular current injections have also been described in neurons within neocortical ectopias (Gabel and LoTurco, 2001). All recorded neurons were able to generate action potentials when positive current injection was applied. Hence, our results suggest that, at this time point, the transplanted cells had reached a degree of maturation similar to that of host neurons described in the literature (Kawaguchi, 1993; Degenetais et al., 2002), and may survive and behave like normal cortical cells.

The fact that electrical stimulation of adjacent host cortex elicited excitatory synaptic responses in grafted cells (Fig. 4B and E) suggests the presence of functional connections between the host and the transplant. The same observation can be made for the connections from the transplant to the adjacent host cortex. These results are supported by the 
A
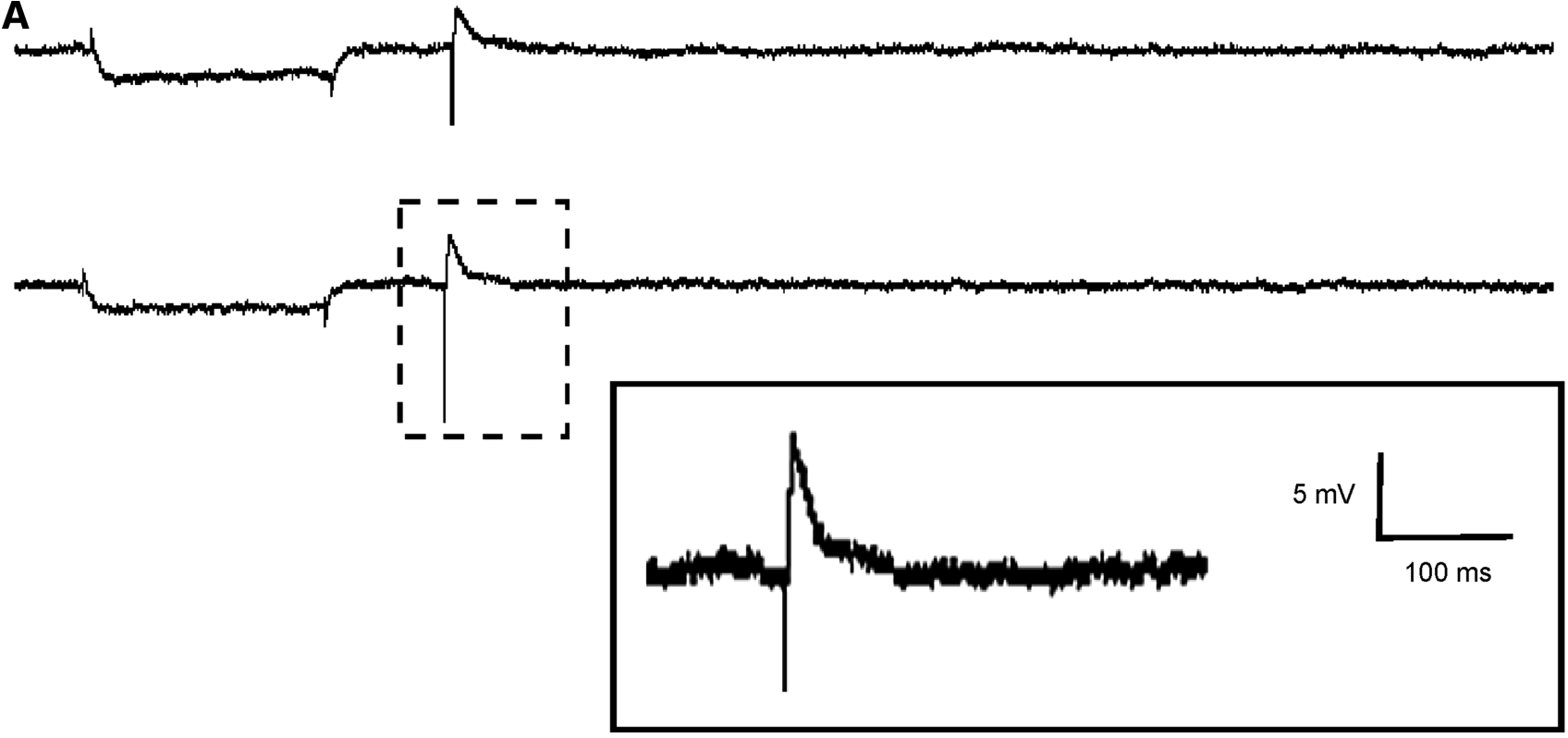

B
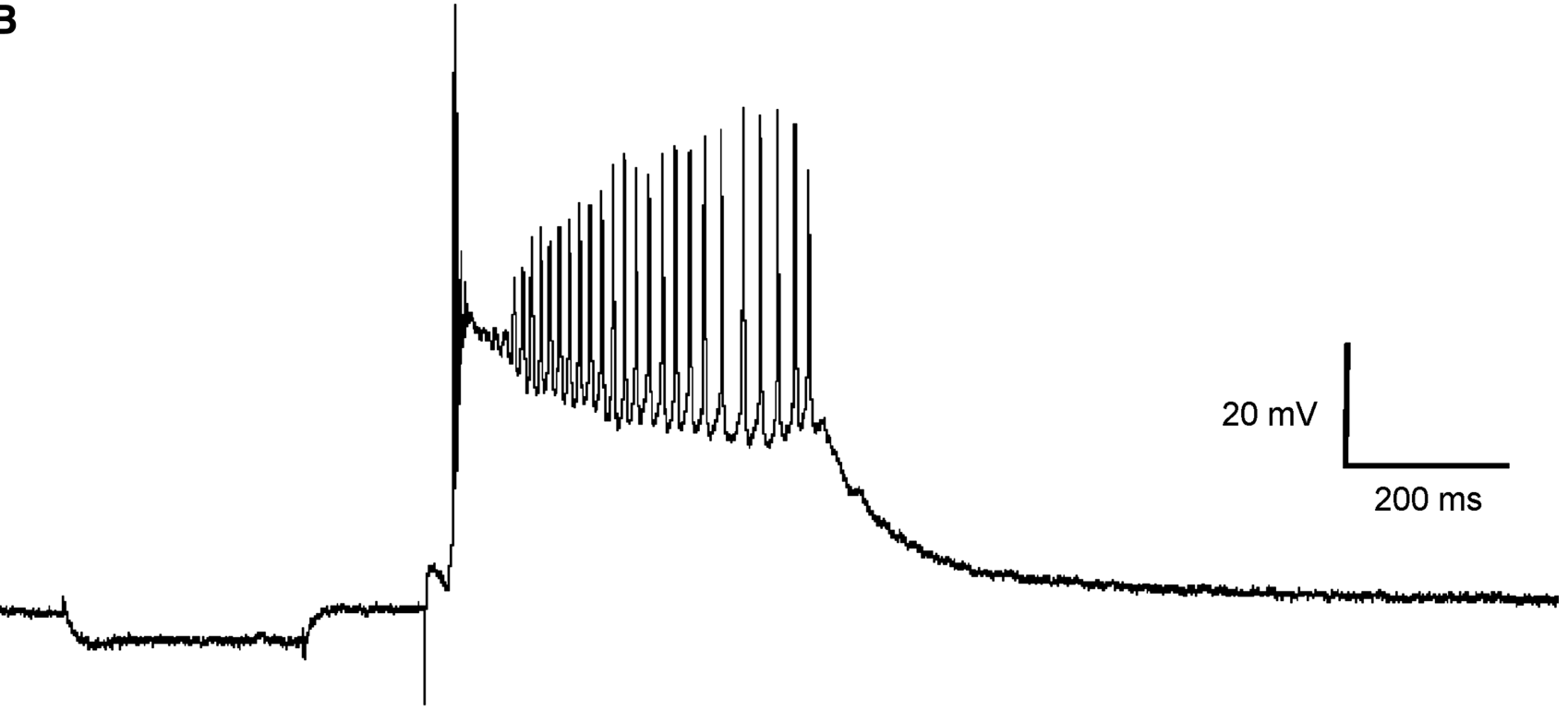

C

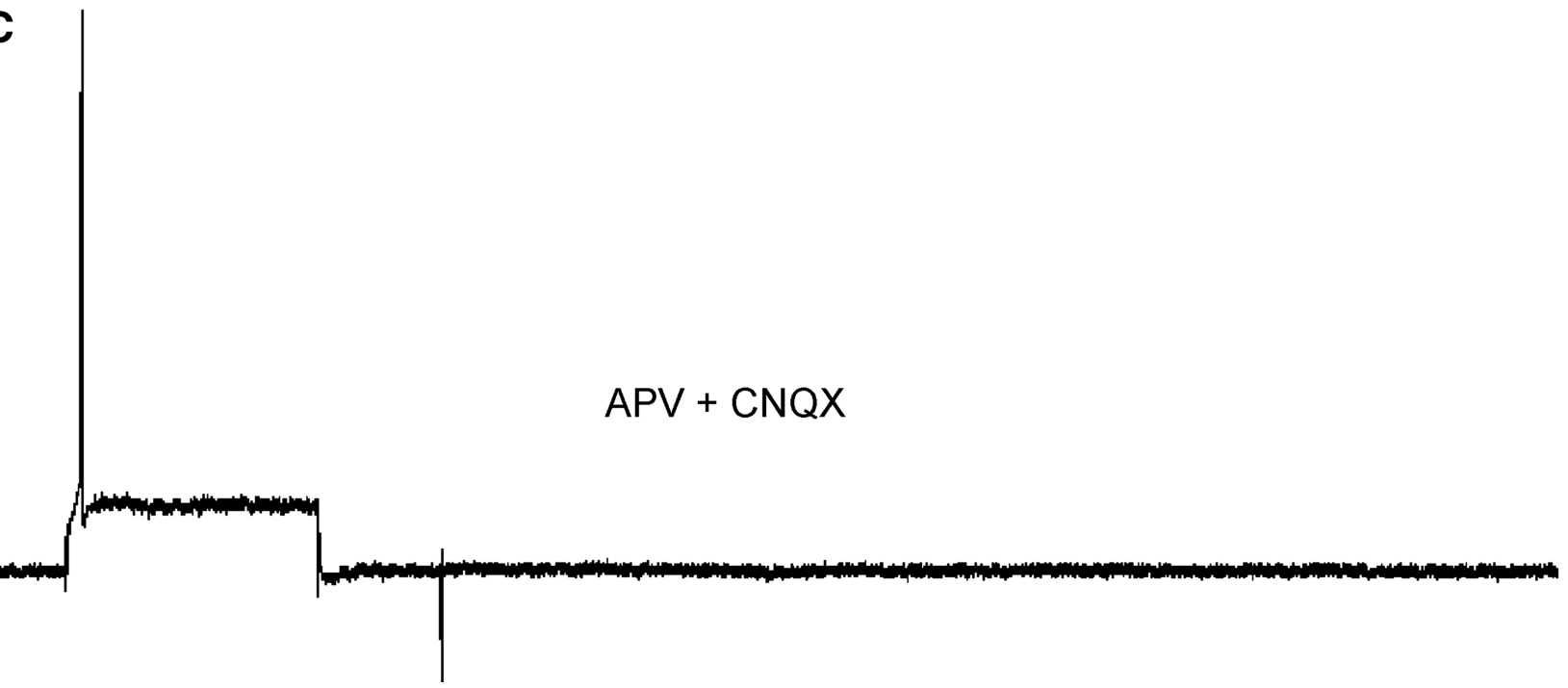



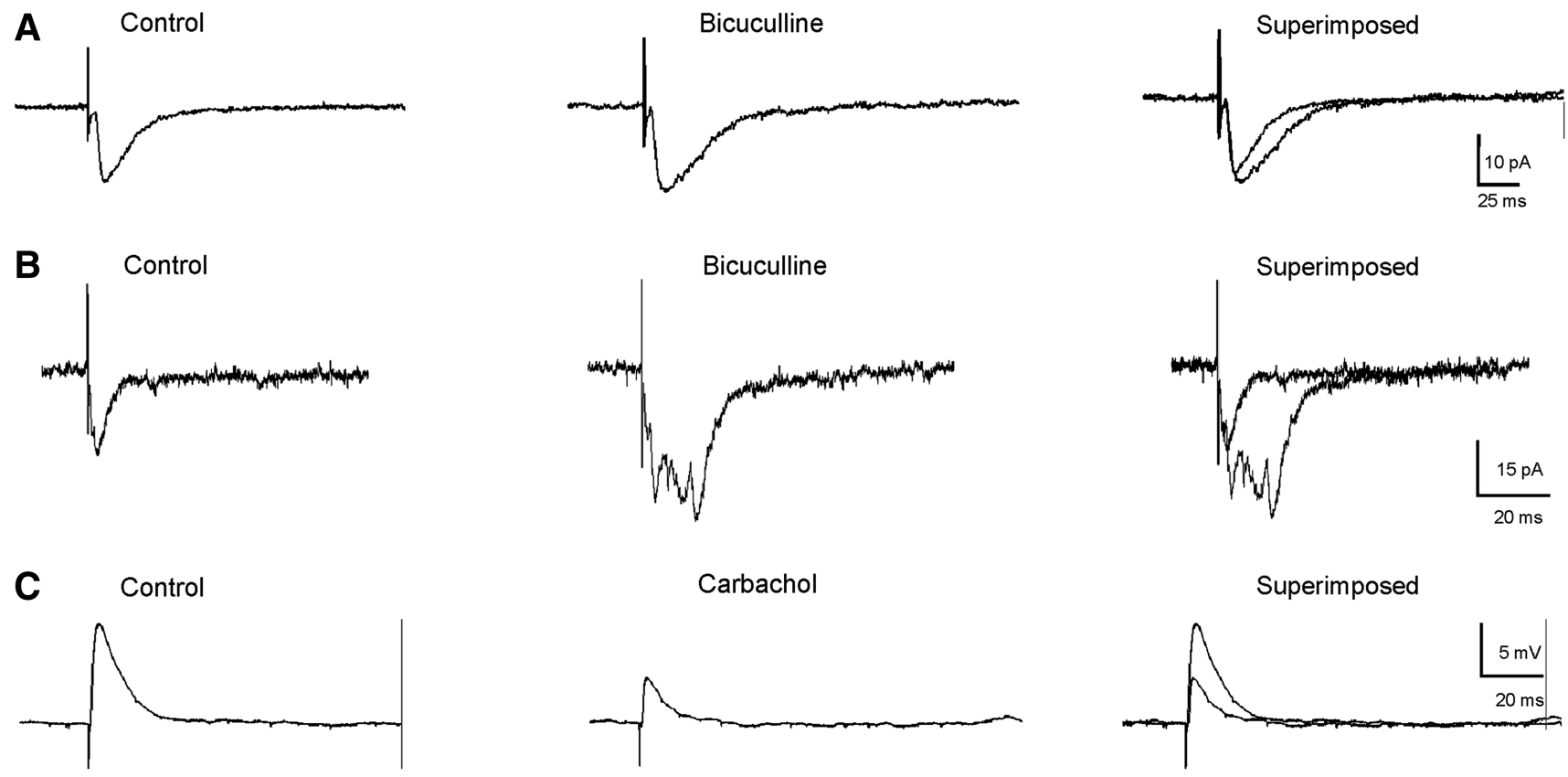

D

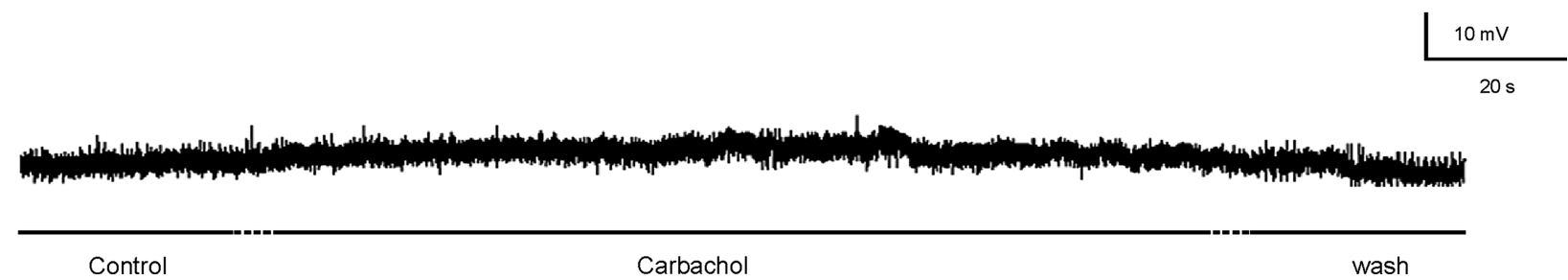

FIG. 7. The evoked synaptic glutamatergic responses in the transplant are modulated by GABAergic and cholinergic drugs. (A) Evoked response increased its amplitude when GABAergic receptors were blocked by bicuculline (10 $\mu \mathrm{M})$ perfusion $(p<0.05)$. (B) Occasionally, bicuculline also generated a prolonged EPSC, presumably by activation of polysynaptic pathways. (C and D) Effects of carbachol on evoked synaptic response and RMP of grafted recorded cells. Carbachol perfusion $(5 \mu \mathrm{M})$ generated a decrease in the amplitude of the synaptic response $(p<0.01)$ and had a depolarizing effect on RMP.

anatomical evidence previously reported using different tracing methods (Heredia et al., 1991; Grabowski et al., 1993; Riolobos et al., 2001; Gaillard et al., 2007), and our current data on biocytin-labeled grafted neurons (Fig. 1E). The lack of evoked responses in some cases when studying hosttransplant connections could be due to the sectioning of fibers during slicing procedures.

Evoked responses were mediated by glutamic acid, because perfusion with NMDA and AMPA-kainate receptor blockers completely removed the response. These results indicate that glutamate is the main excitatory neurotransmitter in the transplant, in agreement with previous reports (Englund et al., 2002).

Inhibitory GABA-mediated transmission in grafted neurons from young transplanted animals has been previously described (Englund et al., 2002; Alvarez-Dolado et al., 2006). In our experiments, none of the evoked synaptic responses was inhibitory, although GABA immunocytochemistry showed a number of GABA-positive grafted neurons in the homotopic transplants. Our results could be attributable to two factors. First, the fact that during the development of cortex, GABA-expressing cells migrate from the subcortical telencephalon into the neocortex. This migration occurs around the 17th day of rat gestation (Anderson et al., 1997; Xu et al., 2004), later than when we obtained our embryonic transplanted cells. Second, the decline of GABA cells in neocortical transplantation (Bragin et al., 1991). However, functional GABAergic receptors capable of regulating the evoked synaptic responses in the grafted neurons were present. Perfusion of the slices with bicuculline (a GABA ${ }_{A}$ blocker) significantly increased the amplitude and duration of the excitatory synaptic response, suggesting the presence of functional GABAergic receptors in the synaptic complex. In addition, $\mathrm{GABA}_{\mathrm{A}}$ receptors were identified in the graft by

FIG. 6. The epileptiform-like response showed a glutamatergic nature, acting on NMDA/non-NMDA receptors. The cell response generated by DC current followed by intra-transplant stimulation. From top to bottom: Synaptic response elicited by transplant stimulation with increased intensity. (A) Sub-threshold stimulation evoked an EPSP. (B) When the stimulus intensity reached a supra-threshold value an epileptiform-like discharge was generated. (C) This evoked response was blocked by the application of CNQX $(10 \mu \mathrm{M})$ and APV $(50 \mu \mathrm{M})$. Note that in the bottom trace the neuron was able to respond to intracellular current injection after blocking the evoked synaptic current (scale bars in B are the same as those for A and C). 

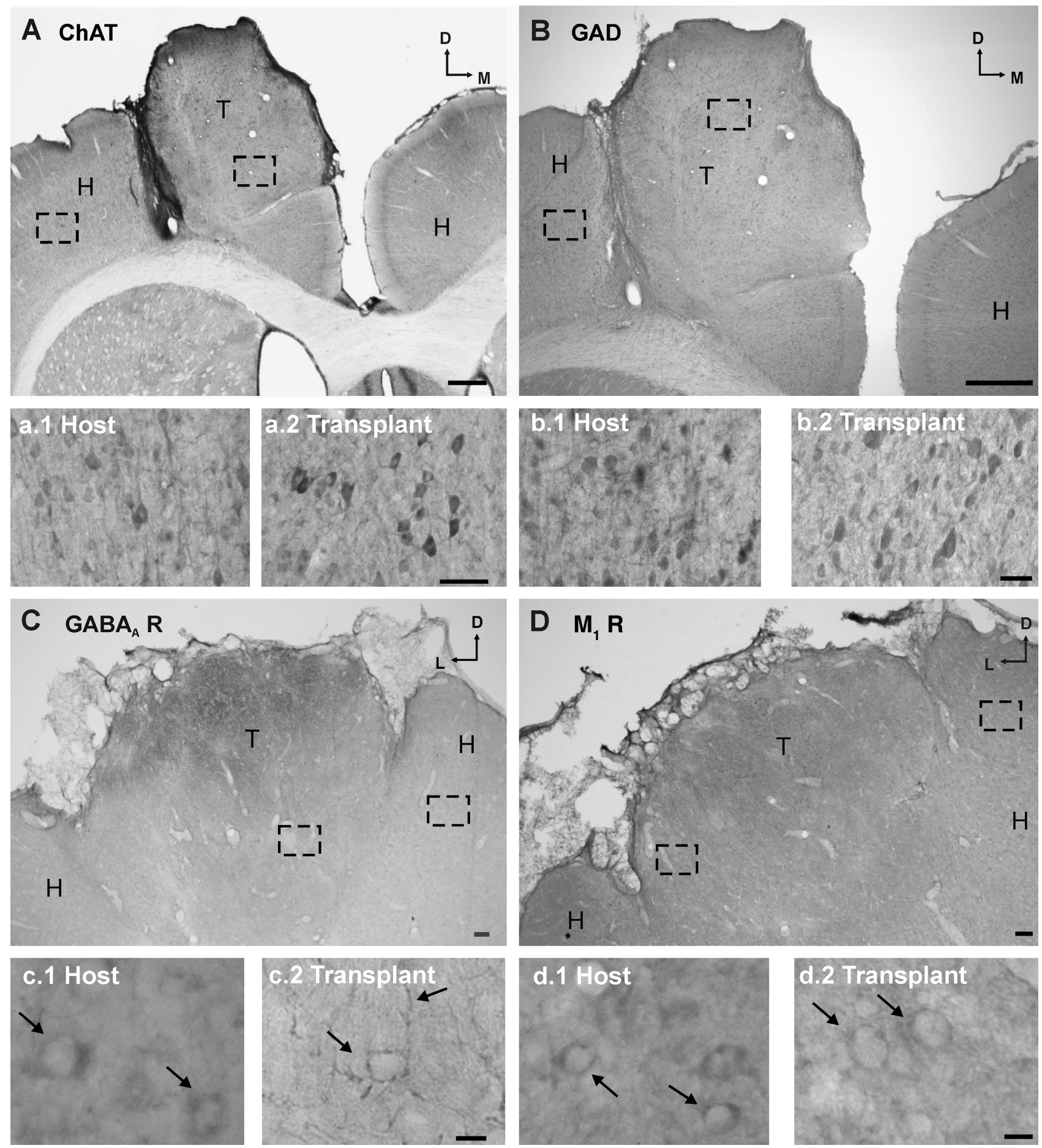

FIG. 8. Immunolabelling of transplanted cells. (A) Photomicrograph of choline acetyltransferase immunoreactivity in a coronal section through a homotopic cortical transplant. (a.1-2) High magnification views of choline acetyltransferasepositive cells in the host (a.1) and the transplant (a.2). (B) Photomicrograph of GAD immunolabeling in a coronal section through a homotopic cortical transplant. (b.1-2) Grafted GAD-immunoreactive cells in the host (b.1) and the transplant (b.2) at higher magnification. (C) Photomicrograph of $\mathrm{GABA}_{\mathrm{A}}$ receptor-immunopositive staining in a coronal section through a homotopic cortical transplant. (c.1-2) High magnification views of $\mathrm{GABA}_{\mathrm{A}}$ receptor-positive host (c.1) and transplanted (c.2) cells (arrows). Some positively-stained processes can also be identified in c.2 (arrow). (D) Photomicrograph of muscarinic $\mathrm{M}_{1}$ receptor-immunoreactive transplanted neurons in a homotopic transplant. (d.1-2) High magnification views of $\mathrm{M}_{1}$ receptorpositive cells (arrows) in the host (d.1) and graft (d.2) (scale bars: A and B, $1 \mathrm{~mm}$; C and D, $100 \mu \mathrm{m} ; \mathrm{a} .2 \mathrm{and} \mathrm{b.2,} 100 \mu \mathrm{m} ; \mathrm{c} .2$ and d.2, $10 \mu \mathrm{m}$; scale bars in a.2, b.2, c.2, and d.2 are the same for a.1, b.1, c.1, and d.1; T, transplant; L, lateral; H, host). 
immunocytochemistry. Similar synaptic changes to exogenously applied GABAergic drugs have been described in neocortex (Sutor and Luhmann, 1995; Englund et al., 2002; Alvarez-Dolado et al., 2006) and that quality seems to be conserved in homotopic cortical grafts in adults. Furthermore, when GABAergic receptors were blocked, some recorded neurons presented prolonged evoked responses with several peaks. This fast polysynaptic response suggests that in the transplant, some cells can be hyper-activated as a consequence of blocking inhibition.

In some cases, suprathreshold stimulation elicited synaptic responses described as epileptiform-like discharges, also called paroxysmal depolarization shift (PDS), which may be related to an imbalance between the excitatory and inhibitory neurotransmitters. Although immunocytochemistry demonstrated the presence of GABAergic cells, their functional role to modulate excitatory activity seem to be exiguous. PDS discharge in presence of GABAergic receptor antagonists has also been described for neocortical brain slices (Schiller, 2004), in neurons from neocortical ectopias (Gabel and LoTurco, 2001), or grafted neurons in young animal cortex (Englund et al., 2002). It has been proposed that in the neocortex PDS response may be mediated by calcium-activated non-specific cation current, since specific blockers for this current were very effective (Schiller, 2004). However, PDS responses evoked in neurons from cortex ectopias were mediated by NMDA-receptor activation (Gabel and LoTurco, 2001). We have shown that PDS in transplanted neurons was not affected by voltage-dependent calcium channel blockers, whereas it could be removed with glutamatergic-receptor antagonists. Taken together, imbalance of inhibitory circuitry, organization of cells in clusters within the graft, and the existence of NMDA calcium-permeable receptors may be factors involved in the generation of intra-transplant epileptiform discharges (Gabel and LoTurco, 2001; Englund et al., 2002; Schiller, 2004).

Furthermore, carbachol modulated the evoked responses and RMP, suggesting a plausible double location for acetylcholine receptors as in other cortical or brainstem structures (Yajeya et al., 2000; Navarro-Lopez et al., 2004). In the presynaptic terminal they would adjust the amount of neurotransmitter to be liberated, and postsynaptically they would control membrane excitability. The enzyme choline acetyltransferase was found in transplanted cells, suggesting that these cells are able to synthesize acetylcholine. Also muscarinic $\mathrm{M}_{1}$ receptors, very common cholinergic receptors in the cortex, were positively immunolabeled in the grafted neurons. Our results support a cholinergic participation in transplant functionality, a concept in agreement with the idea of acetylcholine being specifically involved in the process of behavioral recovery induced by homotopic cortical transplants (Miranda et al., 1997).

Our group has previously shown that homotopic cortical grafted animals established connections from the graft to the host tissue (Riolobos et al., 2001). Furthermore, in the present study we found grafted neuronal processes crossing the graft-host interface (Fig. 1E). Recently the anatomical reestablishment of damaged adult motor pathways by grafted embryonic cortical neurons has been shown (Gaillard et al., 2007). Other authors have reported that in young grafted animals, neuronal precursors can modify levels of electrophysiological activity in the host brain by establishing func- tional synapses with native neurons (Englund et al., 2002; Alvarez-Dolado et al., 2006). Thus much evidence seems to indicate that transplantation of tissue can lead to the establishment of functional connections, and could be used as a cellular vector to deliver therapeutic molecules to wide regions of the brain. Even more, it has been proposed that grafted tissue could lead to the appropriate reconstruction of damaged circuitry in the adult brain. Our demonstration that transplanted cells develop into normal cortical cells that express glutamatergic, cholinergic, and GABAergic receptors are concomitant with an imbalance between excitatory and inhibitory activity in the transplant. However, this latter fact, which has also been demonstrated in young grafted animals (Englund et al., 2002), does not seem to affect functional graftdependent recovery (Plumet et al., 1993; Riolobos et al., 2001).

In summary our results support the hypothesis that development and differentiation of transplanted cells appear to be necessary for the functional integration of the graft into the damaged host brain. In this study we have shown that cells transplanted into adult damaged host brains establish interconnections and develop into normal cortical cells, which suggests that both phenomena could be part of the substrate underlying the functional graft-dependent recovery that has been previously described (Plumet et al., 1993; Riolobos et al., 2001). In any case, this study furthers our understanding of how transplanted cells integrate and fail to integrate, but further studies involving labeled transplanted cells are needed to establish a relationship between anatomical evidence (Gaillard et al., 2007) and functional implications for graft integration following brain injury.

\section{Acknowledgments}

This work was supported by grants FIS-03/0907 (Spanish Ministerio de Sanidad y Consumo, MSC), BFI 2003-01716 (Spanish Ministerio de Educacion y Ciencia, MEC), Red de Terapia Celular 2007-2010 (JCyL, Spain), Mapfre 2007 and Proyecto Jóvenes Investigadores 2007, and USAL2008A13 (University of Salamanca, Spain). J.S.-T. was a Ph.D. fellow from the Agencia Española de Cooperación Internacional (AECI). L.J.-D. is a Juan de la Cierva fellow from Spanish MEC (JCI-2005-1775-25) and J.N.-L. is a postdoctoral fellow from Spanish MSC (CD06/00175). We acknowledge Prof. DelgadoGarcia for helpful comments, the editorial help of G.H. Jenkins, and the technical assistance of Noelia Gonzalez.

\section{Author Disclosure Statement}

No conflicting financial interests exist.

\section{References}

Alvarez-Dolado, M., Calcagnotto, M.E., Karkar, K.M., Southwell, D.G., Jones-Davis, D.M., Estrada, R.C., Rubenstein, J.L., Alvarez-Buylla, A., and Baraban, S.C. (2006). Cortical inhibition modified by embryonic neural precursors grafted into the postnatal brain. J. Neurosci. 26, 7380-7389.

Anderson, S.A., Eisenstat, D.D., Shi, L., and Rubenstein, J.L. (1997). Interneuron migration from basal forebrain to neocortex: dependence on Dlx genes. Science 278, 474-476.

Bjorklund, A., and Lindvall, O. (2000). Cell replacement therapies for central nervous system disorders. Nat. Neurosci. 3, 537-544. 
Bragin, A., Takacs, J., Vinogradova, O., and Hamori, J. (1991). Quantitative estimation of the ratio of GABA-immunoreactive cells in neocortical grafts. J. Neural Transplant. Plast. 2, 235242.

Chagnac-Amitai, Y., Luhmann, H.J., and Prince, D.A. (1990). Burst generating and regular spiking layer 5 pyramidal neurons of rat neocortex have different morphological features. J. Comp. Neurol. 296, 598-613.

Chen, G.J., Jeng, C.H., Lin, S.Z., Tsai, S.H., Wang, Y., and Chiang, Y.H. (2002). Fetal striatal transplants restore electrophysiological sensitivity to dopamine in the lesioned striatum of rats with experimental Huntington's disease. J. Biomed. Sci. 9, 303-310.

Cho, R.H., Segawa, S., Mizuno, A., and Kaneko, T. (2004). Intracellularly labeled pyramidal neurons in the cortical areas projecting to the spinal cord. I. Electrophysiological properties of pyramidal neurons. Neurosci. Res. 50, 381-394.

Connors, B.W., Gutnick, M.J., and Prince, D.A. (1982). Electrophysiological properties of neocortical neurons in vitro. J. Neurophysiol. 48, 1302-1320.

Degenetais, E., Thierry, A.M., Glowinski, J., and Gioanni, Y. (2002). Electrophysiological properties of pyramidal neurons in the rat prefrontal cortex: an in vivo intracellular recording study. Cereb. Cortex 12, 1-16.

Ebrahimi-Gaillard, A., Beck, T., Gaillard, F., Wree, A., and Roger, M. (1995). Transplants of embryonic cortical tissue placed in the previously damaged frontal cortex of adult rats: local cerebral glucose utilization following execution of forelimb movements. Neuroscience 64, 49-60.

Englund, U., Bjorklund, A., Wictorin, K., Lindvall, O., and Kokaia, M. (2002). Grafted neural stem cells develop into functional pyramidal neurons and integrate into host cortical circuitry. Proc. Natl. Acad. Sci. U.S.A. 99, 1708917094.

Fernandez-Ruiz, J., Escobar, M.L., Pina, A.L., Diaz-Cintra, S., Cintra-McGlone, F.L., and Bermudez-Rattoni, F. (1991). Timedependent recovery of taste aversion learning by fetal brain transplants in gustatory neocortex-lesioned rats. Behav. Neural Biol. 55, 179-193.

Gabel, L.A., and LoTurco, J.J. (2001). Electrophysiological and morphological characterization of neurons within neocortical ectopias. J. Neurophysiol. 85, 495-505.

Gaillard, A., Gaillard, F., and Roger, M. (1998). Neocortical grafting to newborn and adult rats: developmental, anatomical and functional aspects. Adv. Anat. Embryol. Cell Biol. 148, $1-86$.

Gaillard, A., Prestoz, L., Dumartin, B., Cantereau, A., Morel, F., Roger, M., and Jaber, M. (2007). Reestablishment of damaged adult motor pathways by grafted embryonic cortical neurons. Nat. Neurosci. 10, 1294-1299.

Garnier, C., Arnault, P., and Roger, M. (1997). Development of the striatal projection from embryonic neurons from the lateral or medial frontal cortex grafted homo- or heterotopically into the medial frontal cortex of newborn rats. Neurosci. Lett. 235, 41-44.

Grabowski, M., Brundin, P., and Johansson, B.B. (1993). Functional integration of cortical grafts placed in brain infarcts of rats. Ann. Neurol. 34, 362-368.

Heredia, M., Santacana, M., and Valverde, F. (1991). A method using DiI to study the connectivity of cortical transplants. J. Neurosci. Methods 36, 17-25.

Kolb, B., Reynolds, B., and Fantie, B. (1988). Frontal cortex grafts have opposite effects at different postoperative recovery times. Behav. Neural Biol. 50, 193-206.
Kawaguchi, Y. (1993). Groupings of nonpyramidal and pyramidal cells with specific physiological and morphological characteristics in rat frontal cortex. J. Neurophysiol. 69, 416431.

Labbe, R., Firl, A., Jr., Mufson, E.J., and Stein, D.G. (1983). Fetal brain transplant: reduction of cognitive deficits in rats with frontal cortex lesions. Science 221, 470-472.

Leonoudakis, D., Zhao, P., and Beattie, E.C. (2008). Rapid tumor necrosis factor alpha-induced exocytosis of glutamate receptor 2-lacking AMPA receptors to extrasynaptic plasma membrane potentiates excitotoxicity. J Neurosci. 28, 2119-2130.

Miranda, M.I., Lopez-Colome, A.M., and Bermudez-Rattoni, F. (1997). Recovery of taste aversion learning induced by fetal neocortex grafts: correlation with in vivo extracellular acetylcholine. Brain Res. 759, 141-148.

Navarro-Lopez, J.D., Alvarado, J.C., Marquez-Ruiz, J., Escudero, M., Delgado-Garcia, J.M., and Yajeya, J. (2004). A cholinergic synaptically triggered event participates in the generation of persistent activity necessary for eye fixation. J. Neurosci. 24, 5109-5118.

Neafsey, E.J., Bold, E.L., Haas, G., Hurley-Gius, K.M., Quirk, G., Sievert, C.F., and Terreberry, R.R. (1986). The organization of the rat motor cortex: a microstimulation mapping study. Brain Res. 396, 77-96.

Paxinos, G., and Watson, C. (1998). The Rat Brain. Academic Press: New York.

Plumet, J., Cadusseau, J., and Roger, M. (1991). Skilled forelimb use in the rat: Amelioration of functional deficits resulting from neonatal damage to the frontal cortex by neonatal transplantation of fetal cortical tissue. Restor. Neurol. Neurosci. 3, 135-147.

Plumet, J., Ebrahimi, A., and Roger, M. (1993). Partial recovery of skilled forelimb reaching after transplantation of fetal cortical tissue in adult rats with motor cortex lesion. Anatomical and functional aspects. Restor. Neurol. Neurosci. 6, 9-27.

Riolobos, A.S., Heredia, M., de la Fuente, J.A., Criado, J.M., Yajeya, J., Campos, J., and Santacana, M. (2001). Functional recovery of skilled forelimb use in rats obliged to use the impaired limb after grafting of the frontal cortex lesion with homotopic fetal cortex. Neurobiol. Learn. Mem. 75, 274-292.

Roger, M., and Ebrahimi-Gaillard, A. (1994). Anatomical and functional characteristics of fetal neocortex transplanted into the neocortex of newborn or adult rats. Rev. Neurosci. 5, $11-26$.

Schiller, Y. (2004). Activation of a calcium-activated cation current during epileptiform discharges and its possible role in sustaining seizure-like events in neocortical slices. J. Neurophysiol. 92, 862-872.

Stein, D.G., Palatucci, C., Kahn, D., and Labbe, R. (1988). Temporal factors influence recovery of function after embryonic brain tissue transplants in adult rats with frontal cortex lesions. Behav. Neurosci. 102, 260-266.

Sutor, B., and Luhmann, H.J. (1995). Development of excitatory and inhibitory postsynaptic potentials in the rat neocortex. Perspect. Dev. Neurobiol. 2, 409-419.

Tuszynski, M.H. (2007). Rebuilding the brain: resurgence of fetal grafting. Nat. Neurosci. 10, 1229-1230.

Wernig, M., Benninger, F., Schmandt, T., Rade, M., Tucker, K.L., Bussow, H., Beck, H., and Brustle, O. (2004). Functional integration of embryonic stem cell-derived neurons in vivo. J. Neurosci. 24, 5258-5268.

Xu, Q., Cobos, I., de la Cruz, E., Rubenstein, J.L., and Anderson, S.A. (2004). Origins of cortical interneuron subtypes. J. Neurosci. 24, 2612-2622. 
Xu, Z.C., Wilson, C.J., and Emson, P.C. (1991). Synaptic potentials evoked in spiny neurons in rat neostriatal grafts by cortical and thalamic stimulation. J. Neurophysiol. 65, 477493.

Yajeya, J., De La Fuente, A., Criado, J.M., Bajo, V., Sanchez-Riolobos, A., and Heredia, M. (2000). Muscarinic agonist carbachol depresses excitatory synaptic transmission in the rat basolateral amygdala in vitro. Synapse 38, $151-160$.
Address correspondence to: Juan Navarro-López, Ph.D. or Javier Yajeya, Ph.D. Departamento de Fisiología y Farmacología Facultad de Medicina Universidad de Salamanca Av. Alfonso X, el Sabio s/n 37007 Salamanca, Spain

E-mail: j.navarro@usal.es or yajeya@usal.es 
